has no business to react so angrily to star wars because its potential for making a first strike from the West feasible is a strictly academic matter, given that the United States would never do such a thing, must sound disingenuous in places such as Omsk and Novosibirsk. Even the assumption, commonly voiced in the United States, that the superior high technology of the United States (in the civilian field at least) will always ensure success in an arms race, may sound aggressive in the East. So should not Western politicians, like those elsewhere, learn not merely to hold their tongues for the duration of the Geneva negotiations, but also spend a little of the time they will save trying to see things from the other fellow's point of view?

\section{Hearts in the wrong place}

The unauthorized use of an artificial heart in Arizona was mistaken humanity.

NATURAL sympathies are with the Arizona surgeon who two weeks ago commandeered an unapproved artificial heart in an effort, ultimately futile as it happened, to keep his patient alive while a replacement human heart could be found. The surgeon, Dr Jack Copeland, has been cast in the traditional American role of the rugged individualist defying authority to do what is right. The Food and Drug Administration (FDA) has obligingly filled in with the part of the pointy-headed bureaucrat by mumbling about technical violations of regulations.

The facts of the case are these: a 33-year-old man who had had two heart attacks and a poor chance of living much longer was given a new human heart in what is becoming an increasingly routine operation. The new heart, however, stopped beating the next day. While Dr Copeland began the search for a replacement, the patient was placed on a heart-lung machine. As the hours passed - and a patient can be kept on the heart-lung machine only a few hours before his red blood cells begin to be damaged Dr Copeland decided the only hope for his patient was the temporary implantation of a mechanical heart.

FDA had authorized only one surgeon - Dr William DeVries of the Humana Heart Institute in Kentucky - to perform that procedure, and only with the Jarvik-7 heart, which was developed at the University of Utah. For reasons that are still unclear, Dr Copeland called St Luke's Hospital in Phoenix, and asked surgeons to bring a mechanical heart under development there. That heart, developed by a dentist, had not been submitted to FDA for approval. It had never been used in a human. Its longest test had been in a calf, for 12 hours. (The Jarvik heart was tested for months in a calf before the first clinical test.) A Jarvik-7 heart was flown in as well, but was not used; some reports say the University of Utah decided against participating in the unapproved surgery.

The Phoenix heart kept Dr Copeland's patient alive for 121 hours; a new human heart was then transplanted but by then lung damage had taken its toll and the strain on the new heart was too much. The patient died, three days after the ordeal began.

Dr Copeland and his surgical team say, simply, that there are higher laws than FDA when a patient's life is at stake. Yet the very point of FDA's regulatory role is to prevent the sort of haphazard and unplanned experiments on humans that in fact took place here. Informed consent - which was obtained from the patient's relatives - is only one necessary element in assuring the ethical practice of experimental medicine. In a crisis, what relative is going to say no to a doctor, especially one so obviously sincere as Dr Copeland in wanting to do the best for his patient? It may be a cruel thing to say, but the end result of what happened in Arizona is that a human being was used as a guinea pig. The FDA rules, hardly extreme, are designed to assure a minimum degree of safety and likely benefit before humans become the experimental subjects.

The irony of the entire episode is that, with better planning, what was attempted at Arizona is really the way that artificial hearts ought to be put to use now: as a stop-gap during hearttransplant surgery. After the Arizona episode, FDA did in fact approve yet another artificial heart - this one developed in Pennsylvania - for just this purpose. Heart transplants can now offer real hope for otherwise hopeless patients. They have also succeeded in many cases in allowing patients to resume nearnormal, active lives. The same simply cannot be said for the "permanent" implantation of artificial hearts at this primitive stage of development. An implant that must be tethered to a huge external air compressor (apart from posing a constant risk of infection at the point where the tubes enter the patient) exacts a devastating psychological toll.

The argument, of course, is that the early heart transplant operations could have been criticized on similar grounds - that they were grandstand medicine, more stunts than attempts to improve the patients' well-being - but that what was learned in these many early attempts paved the way for today's successes. The analogy is not exact, however. The medical spectaculars at the Humana Heart Institute (which has permission from FDA to go ahead with more "permanent" artificial heart implantations) are turning out to be gruesome endurance tests. No matter how much is learned about surgical technique, proper medication and the like from these operations, the technology of the heart itself is simply ton primitive to justify the goal of permanent implantation. They are attempting to fine-tune a procedure that is questionable even if it worked perfectly.

Admitted'y, clinical performance data need to be collected hand-in-hand with efforts to improve the technology. But limiting the artificial heart to temporary use seems a reasonable compromise to achieve this goal without turning humans into guinea pigs.

\section{Sustaining Africa}

\section{The UN now has money with which to feed} Africa. How should it be spent?

THE United Nations has surprised itself by collecting (in promises) more than twice the $\$ 1,000$ million it had asked for so as to reinvigorate African agriculture. No doubt part of the success stems from this season's appalling famine in Ethiopia, worse than last season's by a long way if only because it was more elaborately covered by television cameras. Unfortunately, it is far from easy to tell how such large resources could be spent wisely and quickly enough to make much difference within the lifetime of those who have worked to recruit the funds. The temptation will be to spend the money on the classical agricultural projects of development - irrigation dams and drainage schemes. But the needs are social and even political.

Ironically, most industrialized countries honour their farmers and are indeed over-generous towards them, but developing countries, where the need for food is greater, tend to worry instead about the prices that urban people (and voters) pay for the food they eat. The result is price control that pauperizes the farming population, driving them to the cities to look for welfare instead of growing food. On many occasions, matters have been made worse by spectacular mismanagement, as of Ghana's cocoa crop, once the foundation of the country's relative prosperity. In Ethiopia, part of the cause of this year's famine must be the hostility of the government (and, fair play, of the farmers) towards the middlemen who traditionally bought grain from farms and sold it on to cities; nobody remembered that the middlemen were the distribution system, which collapsed when the intermediaries were abolished. There are also, of course, climatic and agricultural problems of great severity.

The most urgent need, and the best use of the UN money, is for a technical infrastructure to support peasant agriculture, Africa's equivalent of the extension services of Europe and North America (but also in place in India before the green revolution). The second need is for better plant breeding, done in Africa (but not necessarily by Africans.) The third is that African governments should recognize that the whole country will go hungry if farmers are driven to starvation by low prices. There might even be some change left over for a few dams. 